\title{
Immunopathology of guinea pig autoimmune enterocolitis induced by alloimmunisation with an intestinal protein
}

\author{
M S NÉMIROVSKY, AND J S HUGON \\ Departments of Anatomy and Cell Biology and Pathology, Faculty of Medicine, University of Sherbrooke, \\ Sherbrooke, Quebec, Canada
}

SUMMARY An enterocolitis has been induced in guinea pigs by alloimmunisation with a mucosal protein. A single dose of immunogen fails to provoke a synthesis of precipitant antibodies, but a high percentage of animals, injected with two or more doses, develop these antibodies. A specific cell mediated immune response was already detectable 30 days after a single dose of immunogen. At later periods and after multiple doses of immunogen positive results were still found, although in a lesser percentage of the animals. The pathology was characterised by the appearance of multiple mucosal ulcerations, congestion, oedema and localised haemorrhage. The target organs were mainly ileum and descending colon. At later periods a combination of mononuclear cell infiltration, fibrocytic proliferation and granuloma formation appeared together with the other lesions. When an intraluminal challenge was made 48 hours before death, a heavy mononuclear cell infiltration was present in the contact area. The lesions appeared to extend to areas which usually remained unaffected. The characteristic immunopathology of this autoimmune enterocolitis in guinea pigs possesses some of the features of human inflammatory bowel diseases and makes it a useful model for further studies.

Non-specific inflammatory bowel diseases possess a number of immunological features compatible with an autoimmune process. ${ }^{12}$

Organ specific antigens appear to be present in intestinal mucosa. ${ }^{3}$ Their characterisation and tissue localisation has been determined in rats. ${ }^{4}$ The experiments presented here are designed to study the immunopathology of guinea pigs alloimmunised with a mucosal protein. The aim is to find an immunological model of experimental inflammatory bowel disease. Their distinctive feature is a chronic process initiated by alloimmunisation by an enteric protein with the intestinal tract being the target organ.

\section{Methods}

ANIMALS

Adult Hartley guinea pigs (Canadian Breeding, St

Address for correspondence: Dr Mario S. Némirovsky. Département danatomie et de biologie cellulaire, Faculté de médicine, Université de Sherbrooke. Sherbrooke. (Québec) Canada J1H $5 \mathrm{~N} 4$

Received for publication 4 February 1986.
Constant, Quebec) of either sex, weighing 300-400 g at the beginning of the immunisation, were used throughout the experiments. They were maintained on a normal laboratory diet.

IMMUNOGEN PREPARATION

An intestinal protein immunogen (mucosal antigen: MA) was prepared from whole small intestine by modification of the procedure described by Forstner et al. ${ }^{5}$ Briefly, the postmicrosomal supernatant of guinea pig mucosal scrapings was applied to a $2.5 \times 40 \mathrm{~cm}$ column of Bio-Gel A-15 (Bio-Rad, Richmond, California) and eluted with $20 \mathrm{mM}$ Tris- $\mathrm{H} \mathrm{Cl}-\mathrm{Na} \mathrm{Cl}$ buffer $\mathrm{pH} \mathrm{8.0.} \mathrm{The} \mathrm{major} 254$ and $280 \mathrm{~nm}$ peak fractions were dialysed against distilled water and lyophilised. The powder was diluted in $10 \mathrm{ml}$ of the same buffer, added to a $2.6 \times 100 \mathrm{~cm}$ column of Sephacryl S-200 Super fine (Pharmacia, Uppsala, Sweden) and eluted with the above mentioned buffer. Three $\mathrm{ml}$ fractions were collected with a LKB 7000 Ultrorac fraction collector (LKB, Bromma, Sweden) and a Pharmacia P-3 peristaltic pump. Each fraction was read at $254 \mathrm{~nm}$ and 
$280 \mathrm{~nm}$. Three peaks were obtained. The major peak eluting near the void volume was used as mucosal antigen immunogen after dialysis and lyophilisation. Protein concentration was measured by the method of Lowry et al. ${ }^{6}$

\section{IMMUNISATION SCHEDULE}

The animals were divided into seven groups. Group I was injected with a single dose of $10 \mathrm{mg} \mathrm{N}$ of mucosal antigen dissolved in $0.5 \mathrm{ml} \mathrm{Na} \mathrm{Cl} 0.15 \mathrm{M}$ and emulsified in an equal volume of Freund's complete adjuvant (FCA) H37Ra (Difco Laboratories, Detroit, Michigan). The adjuvant contains $1 \mathrm{mg} / \mathrm{ml}$ of killed human M tuberculosis. The emulsion was injected intradermally into the four foot pads and into the skin of the back at multiple sites, each animal receiving a total of $1 \mathrm{ml}$. They were killed at day 30 (10 animals).

Group II guinea pigs received two doses of $5 \mathrm{mg} \mathrm{N}$ MA+FCA with a 30 day interval and killed at day 60 (five animals); group III guinea pigs received three doses of $5 \mathrm{mg} \mathrm{N} \mathrm{MA}+\mathrm{FCA}$ at 45 days interval and were killed at day 120 (5 animals); group IV was constituted by animals treated as those of group III but killed at day 225 (five animals). Three additional groups were formed as follows: group $\mathrm{V}$ animals received a single dose of $5 \mathrm{mg} \mathrm{N} \mathrm{MA}+\mathrm{FCA}$ and killed at day 30 (five animals); group VI guinea pigs received two doses of $5 \mathrm{mg} \mathrm{N}$ MA+FCA with a 30 day interval and killed at day 75 (five animals) and finally group VII guinea pigs were immunised as group VI animals, but killed at day 90 (five animals).

Animals belonging to experimental groups V, VI and VII were anaesthesised with an intraperitoneal injection of Nembutal (Abbott, Montreal, Quebec) and challenged 48 hours before being killed with $1.25 \mathrm{mg} \mathrm{N}$ of mucosal antigen dissolved in $1.25 \mathrm{ml}$ of phosphate-buffer saline (PBS) and mixed with 250 $\mathrm{mg}$ of a dental paste (Alginate ${ }^{\circledR}$, Cook-White Laboratories, Aurora, Ontario). Before hardening, the soft mixture was transferred to a $2 \mathrm{ml}$ glass syringe and injected into the descending colon lumen at a distance of $12 \mathrm{~cm}$ from the anus through a feeding tube French 6 (Progressive Products, Montreal, Quebec). The animals were fasted for 24 hours before cannulation.

Two control animals non-immunised and two immunised with Freund's complete adjuvant alone emulsified in $\mathrm{Na} \mathrm{Cl} 0 \cdot 15 \mathrm{M}$ were included in each experimental group. Those injected with Freund's complete adjuvant alone received equivalent amounts of $M$ tuberculosis as well as the same number of injections as the experimental groups.

All animals receiving multiple doses of antigen emulsified in Freund's complete adjuvant or
Freund's complete adjuvant alone were injected after the second dose with half the volume of the emulsion as compared with the first one. The chosen sites of injection were the skin of the back and the route of injection was subcutaneous and intradermal.

\section{IMMUNOLOGICAL STUDIES}

At the time of being killed, the animals were bled. The sera was inactivated for 30 minutes at $56^{\circ} \mathrm{C}$ and kept at $-30^{\circ} \mathrm{C}$ until used.

Double immunodiffusion plates were prepared ${ }^{7}$ and the sera were allowed to diffuse in the presence of mucosal antigen. Heterologous rabbit anti-MA sera were obtained by multiple injections of mucosal antigen into New Zealand rabbits and used as positive controls. The sera from the experimental animals were collected by intra-cardiac puncture before immunisation and served as negative controls.

The lymphocyte transformation test was used as an in vitro correlate of specific cell-mediated immunity. ${ }^{8}$ The lymph nodes draining the immunisation sites and the spleen were used as lymphocyte sources. Different concentrations of mucosal antigen were added to microplates containing different concentrations of lymphocytes. Besides purified protein derivative of $M$ tuberculosis (PPD, Central Veterinary Laboratory, Ministry of Fisheries, Weybridge, UK), various polyclonal mitogens were added in order to assess the functional viability of lymphocytes. After $68 \mathrm{~h}$ of incubation at $37^{\circ} \mathrm{C}$, a four hour pulse of $2 \mu \mathrm{Ci}$ per well of ${ }^{3} \mathrm{H}$-thymidine, (New England Nuclear, Boston, Mass.; specific activity $28 \cdot 8 \mathrm{Ci} / \mathrm{mmol}$ ) was given. The radio-activity of the cells collected over glass filters was measured with a Beckman Scintillation Spectrometer (Beckman Instruments, Irvine, California). The rate of incorporation of ${ }^{3} \mathrm{H}$-thymidine was expressed as the stimulatory index (SI) according to the following equation

$$
\text { SI: } \frac{\mathrm{cpm} \text { cells }+\mathrm{MA}}{\mathrm{cpm} \text { cells in medium alone }}
$$

In vivo delayed hypersensitivity reactions to the immunogen as well as to PPD were studied within two days before being killed by intradermal injections into the shaved abdominal skin of $100 \mu \mathrm{l}$ PPD $25 \mu \mathrm{g} \mathrm{N}$ and $100 \mu \mathrm{l}$ mucosal antigen $10 \mu \mathrm{g} \mathrm{N}$. Twenty four and 48 hours later, the diameter of the area of induration and erythema was measured with skin clippers.

PATHOLOGICAL STUDIES

The whole gut was removed and placed on a glass 
surface over an ice bath. The lumen was opened, washed with cold PBS and a macroscopic examination was performed in order to identify haemorrhagic areas. These areas, as well as three to five samples from each of the following anatomic segments were collected: duodenum, jejunum, ileum, terminal ileum, caecum, ascending, transverse and descending colon and rectum. The pieces were placed on cardboards (mucosal surface upside), submerged in Bouin's solution, and embedded in paraffin. Six $\mu \mathrm{m}$ sections were then stained with hematoxylin-eosin or PAS-hematoxylin for microscopical examination.

Histological sections were examined in a coded fashion by one of us (MSN), without knowledge of the source of the slide, and whether from experimental or control animals.

Special care was taken in order to collect a maximum number of specimens upstream and downstream from the descending colon area neighbouring the contact zone with the MA-Alginate tablets.

At the time of death of the animals belonging to the experimental groups V, VI and VII, as well as their controls, the cannula used for the intraluminal challenge was re-introduced in order to precisely localise the original contact area with the immunogen. Only those animals retaining the tablets for at least six hours were studied.

For each of the experimental and control animals, representative pieces of kidney, liver, adrenal glands and lungs were fixed and processed as above.

Body weight was recorded daily for 10 days after immunisation and weekly later on. Visual examination of the anus was carried out in order to detect macroscopic blood loss. Weekly or biweekly cardiac blood samples were taken in order to measure the red cell volume (haematocrit).

\section{Results}

HUMORAL IMMUNE RESPONSES

Antibodies giving multiple precipitation bands were present in sera of guinea pigs receiving two doses of mucosal antigen (four of five animals of group II; five of five animals of group VI; four of five animals of group VII). As shown in the Table, a similar percentage of positive sera was detected within the group III animals (four of five).

The number of animals giving positive results in Outcherlöny tests, when studied 225 days after the beginning of the immunisation, was reduced to half (two of five).

Immunoelectrophoretic and serologic studies (Némirovsky, unpublished) reveal that those antibodies were mainly $\operatorname{IgG} \gamma 2$.

All samples collected from animals receiving a single dose of mucosal antigen as well as those from the controls gave negative results. An identity reaction was detected between the precipitation bands of heterologous and isologous anti-mucosal antigen antibodies, although some reactions of nonidentity can be observed (Fig. 1).

\section{CELL MEDIATED IMMUNE RESPONSES}

The intradermal injection of mucosal antigen to alloimmunised animals produced a cutaneous reaction which was characterised by congestion and induration and which reached its peak $24 \mathrm{~h}$ after challenge. Thirteen out of 15 animals receiving a single dose of mucosal antigen and studied 30 days later gave positive skin tests (diameter of erythema $\geqslant 10 \mathrm{~mm}$; diameter of induration $\geqslant 5 \mathrm{~mm}$ ). This in vivo delayed hypersensitivity reaction also gave positive results in guinea pigs receiving multiple doses of the immunogen, including those studied 225 days after the beginning of the immunisation

Table Immunopathological features of alloimmunised guinea pigs*

\begin{tabular}{|c|c|c|c|c|c|c|c|}
\hline & \multicolumn{7}{|c|}{ Experimental groups* } \\
\hline & $l$ & II & $I I I$ & $I V$ & $V$ & $V I$ & $V I I$ \\
\hline Number of immunisation* & 1 & 2 & 3 & 3 & 1 & 2 & 2 \\
\hline Day of sacrifice after the beginning of immunisation & 30 & 6() & 120 & 225 & 30 & 75 & 9() \\
\hline Intracolonic challenge with $\mathrm{MA}+$ alginate* & - & - & - & - & + & + & + \\
\hline Number of animals developing precipitant antibodies* & $0 / 10$ & $4 / 5$ & $4 / 5$ & $2 / 5$ & $0 / 5$ & $5 / 5$ & $4 / 5$ \\
\hline $\begin{array}{l}\text { Number of animals giving positive skin tests to injection of } \\
\text { mucosal antigen }(\theta \text { erythema } \geqslant 10 \mathrm{~mm}, \theta \text { induration } \geqslant 5 \mathrm{~mm})\end{array}$ & $9 / 10$ & $3 / 5$ & $3 / 5$ & $2 / 5$ & $4 / 5$ & $3 / 5$ & $2 / 5$ \\
\hline Number of animals giving a stimulatory index $\geqslant 3 \cdot 0$ & & & & & & & \\
\hline in a lymphocyte transformation test ${ }^{*}$ & $9 / 10$ & $4 / 5$ & $2 / 5$ & $2 / 5$ & $5 / 5$ & $3 / 5$ & $2 / 5$ \\
\hline Number of animals showing macroscopic mucosal haemorrhages & & & & & & & \\
\hline in at least one anatomical segment of the intestinal tract* & $3 / 10$ & $4 / 5$ & $2 / 5$ & $2 / 5$ & $2 / 5$ & $3 / 5$ & $3 / 5$ \\
\hline Number of animals showing histopathological lesions in & & & & & & & \\
\hline at least one anatomical segment of the intestinal tract* & $8 / 10$ & $4 / 5$ & $5 / 5$ & $5 / 5$ & $4 / 5$ & $5 / 5$ & $3 / 5$ \\
\hline
\end{tabular}

*Sec Methods for details. 


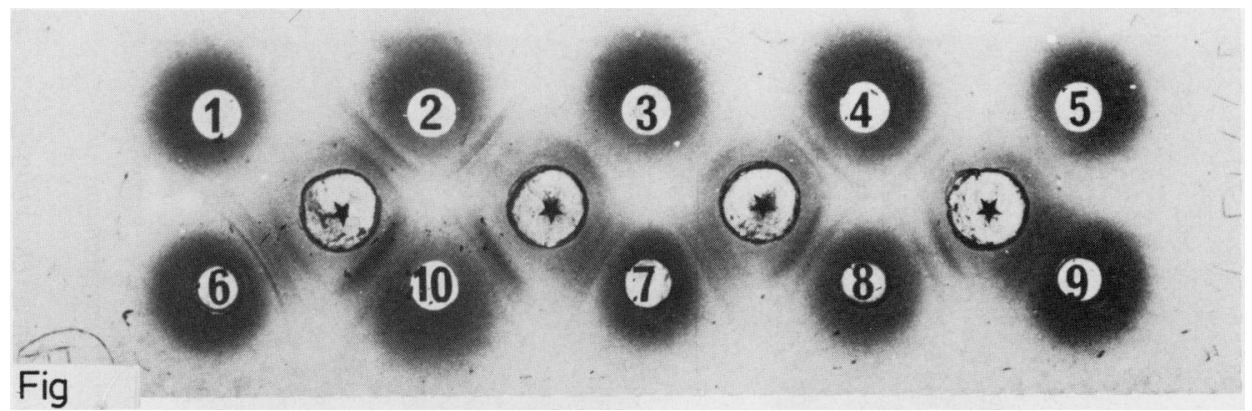

Fig. 1 Ouchterlöny immunodiffusion analysis of guinea pig and rabbit anti-MA sera. $\star: M A, 5 \mathrm{mg} \mathrm{N} / \mathrm{ml} P B S$. $1: \mathrm{guinea}$ pig anti-MA serum, 30 days after a single dose of $M A+F C A$. 2 to 4: guinea pig anti-MA sera 60 days after 2 doses of $M A+F C A .5$ to 9: guinea pig anti-MA sera 120 days after 3 doses of MA+FCA. 10: rabbit anti-MA serum.

schedule, though the percentage of animals giving positive skin tests was smaller.

Positive results were recorded in sites of PPD challenge, including those controls immunised with FCA alone (diameter of erythema $\geqslant 15 \mathrm{~mm}$; diameter of induration $\geqslant 7 \mathrm{~mm}$ ).

Any control animal gives positive skin tests when challenged with mucosal antigen (diameter of erythema $\leqslant 5 \mathrm{~mm}$; diameter of induration $\leqslant 1 \mathrm{~mm}$ ).

A proliferative response was observed when lymph node and spleen lymphocyte suspensions, obtained from alloimmunised animals, were incubated in the presence of mucosal antigen. Preliminary tests showed that the optimal concentration for a positive lymphocyte transformation microtest was $2.5 \times 10^{5}$ cells and $5 \mu \mathrm{g} \mathrm{N}$ mucosal antigen per well in a total volume of $200 \mu \mathrm{l}$. Functional viability of lymphocytes was checked by running parallel cultures with PPD and polyclonal mitogens, but these results are not expressed in the Table.

Whereas the number of animals giving a stimulatory index $\geqslant 3.0$ was high in single-dose alloimmunised guinea pigs in presence of mucosal antigen $(13 / 15)$, roughly half of those receiving multipe doses of mucosal antigen as immunogen gave a degree of proliferative response similar to the above mentioned animals, up to 225 days after the beginning of immunisation (Table).

All control guinea pigs, either non-immunised or injected with FCA alone showed, in presence of $\mathrm{MA}$, a proliferative response close to that of lymphocytes incubated with medium alone (SI $\leqslant 1 \cdot 1)$.

\section{PATHOLOGICAL STUDIES}

The macroscopic examination of the intestinal lumen at the moment of death revealed scanty star-like areas of haemorrhage of up to $5 \mathrm{~mm}$ diameter, which were localised mainly in the ileum near the ileocaecal junction. A little over $30 \%$ of single dose injected guinea pigs $(5 / 15)$ showed these areas. In multiple dose immunised animals, the percentage revealing some degree of visible mucosal haemorrhage increased to $56 \%(14 / 25)$. In the latter group the haemorrhage areas extended to caecum and colonic segments. None of the control animals, including those challenged by the intracolonic route, revealed similar haemorrhagic areas.

Visible blood was never observed in the perianal zone during the animal's life. Periodic body weight and haematocrit checks indicated that limited mucosal haemorrhage was not a life threatening event. A negative balance in body weight never exceeding $10 \%$ of that of the beginning of the experiments was noticed after the first immunisation series. That holds true for guinea pigs immunised either with MA+FCA or with Freund's complete adjuvant alone. Within the 10 following days the balance became positive. The body weight loss was rather unusual after two series of immunisation and was never observed after three doses of immunogen. At day 30 after immunisation, the body weight was five to $10 \%$ higher than that of the beginning. The percentage of increase in body weight was of $20-25 \%$ at day $60,30-35 \%$ at days 75 or $90,50-70 \%$ at day 120 and $80-100 \%$ at day 225 .

Similar increases were recorded in control animals (either non-immunised or injected with Freund's complete adjuvant alone).

No changes in haematocrit readings were detected in the experimental animals (non-immunised controls: mean $48.5 \%$ SD 1.86; controls immunised with Freund's complete adjuvant alone, mean $48.6 \%$ SD 1.67; immunised with MA+FCA, mean $48 \cdot 3 \%$ SD $1 \cdot 63$ ).

Guinea pigs immunised with a single dose of 

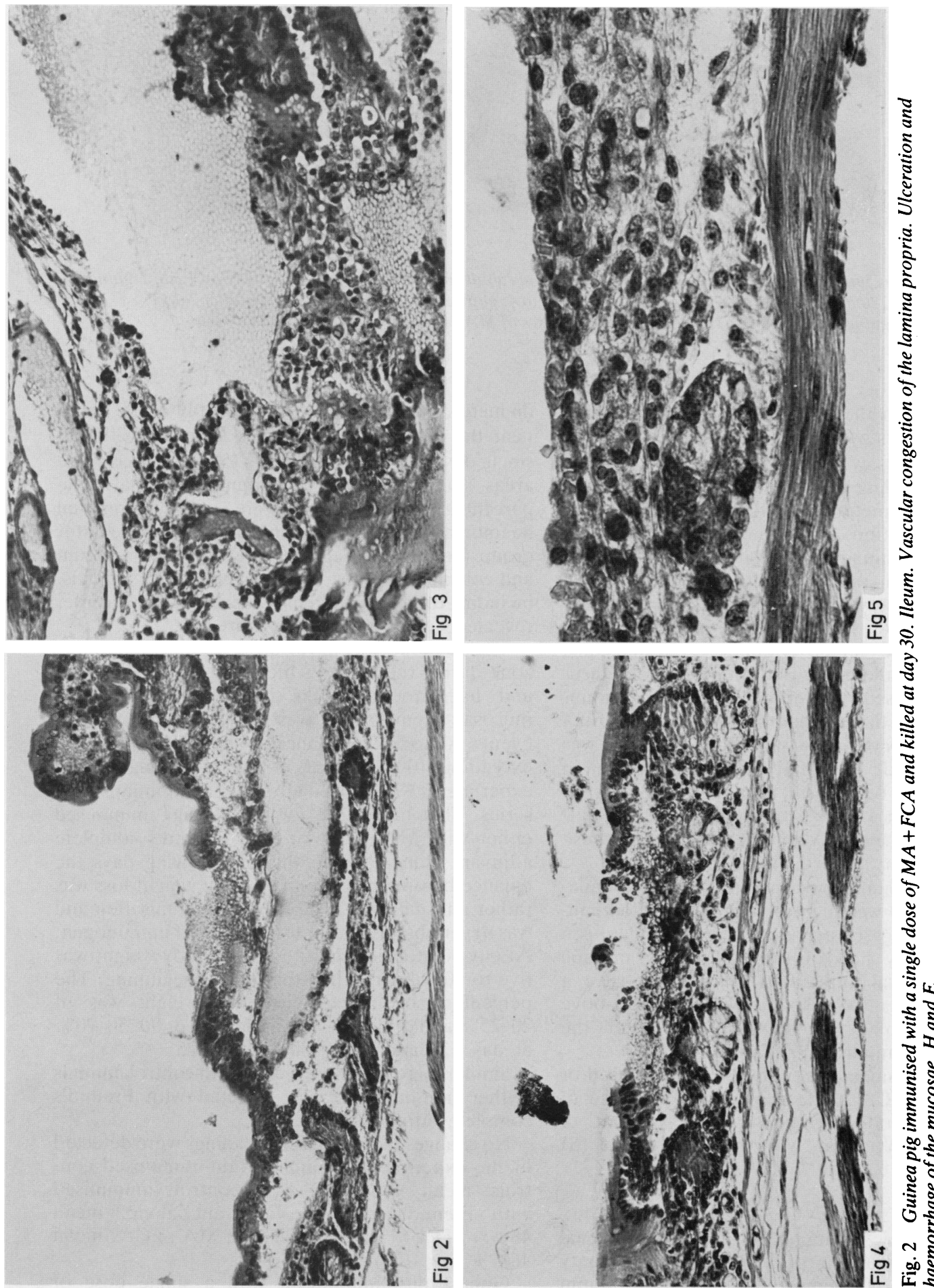

\section{ก}



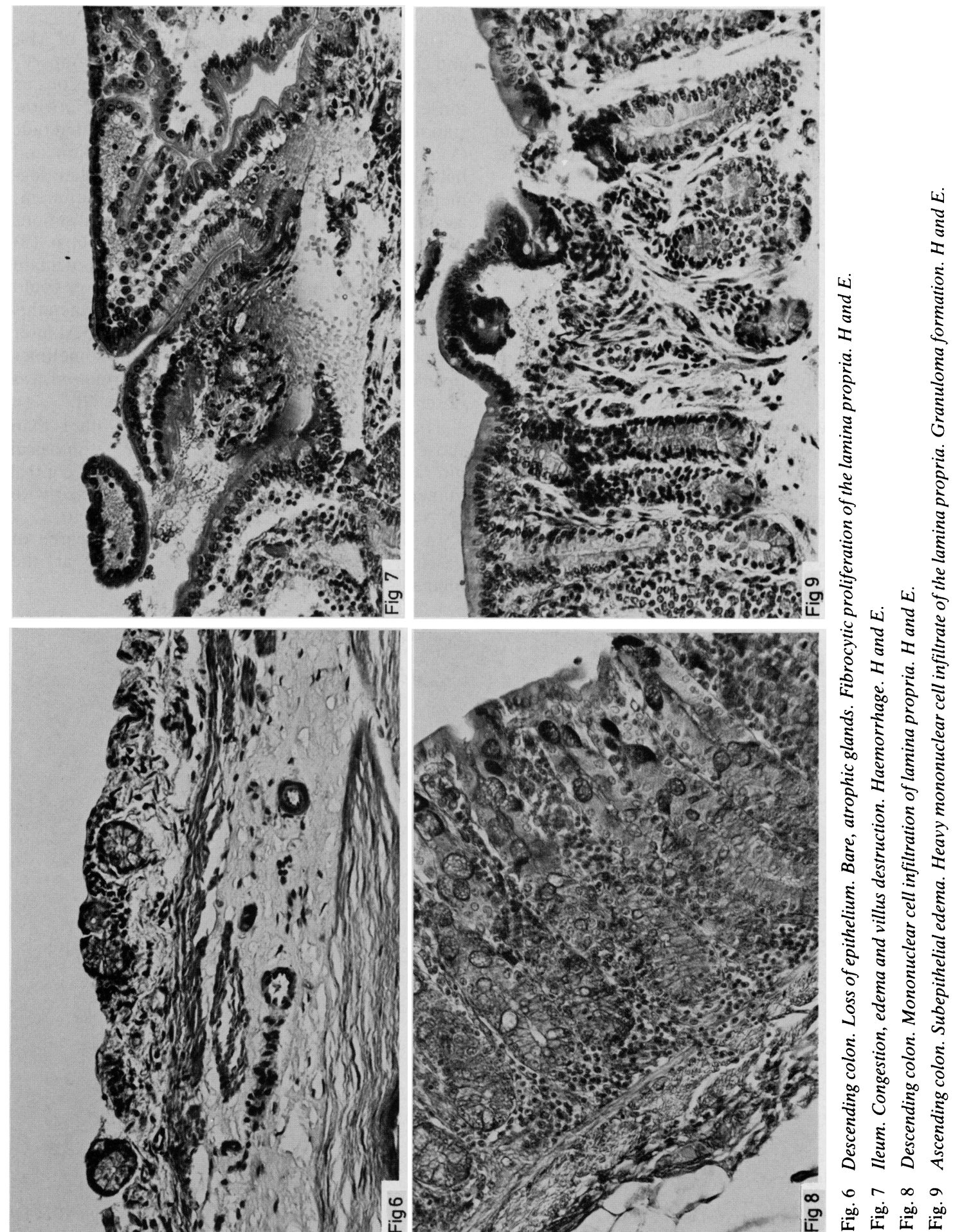

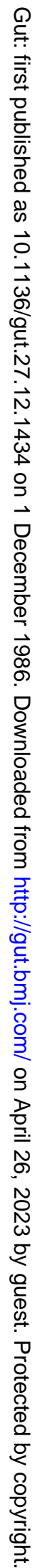


mucosal antigen developed lesions which were preferentially localised in the ileum and descending colon. They were characterised by vascular congestion of the lamina propria, ulceration and haemorrhage (Fig. 2).

Sometimes the loss of epithelium and the neighbouring lamina propria, including Leiberkhün glands, was quite extensive, but without microscopic evidence of blood loss.

Thirty days after immunisation, mononuclear cell infiltration of the lamina propria was an infrequent event. Twelve of the 15 guinea pigs belonging to groups I and V developed histological alterations in at least one intestinal segment.

In animals receiving multiple doses of mucosal antigen, epithelial loss, congestion, haemorrhage and destruction of villus architecture were prevailing lesions especially in the ileum (Fig. 3). The caecum appeared to be more frequently affected than in single injected animals (Fig. 4).

Even though already apparent 60 days after the beginning of the immunisation, lesions, characterised by extensive loss of the mucosal epithelium, mononuclear cell infiltration, cryptal degeneration and fibrocytic proliferation of the lamina propria, increased in severity at later periods (Figs 5 and 6 ).

The number of animals developing at least one form of histopathological alterations was as high as that of single challenged guinea pigs: 22/25.

The animals receiving one or two doses of MA and challenged by the intracolonic route (groups $\mathrm{V}$, VI and VII) developed the same kind of lesions as those belonging to groups I to IV. (Fig. 7) Notwithstanding, two characteristics have to be pointed out: (1) the congestion, edema, villus destruction and haemorrhage could also be detected in other segments of intestine such as duodenum, jejunum, ascending or transverse colon. These localisations were unusual in other experimental groups; (2) within the contact areas with the MA-alginate tablet, a heavy mononuclear cell infiltration could be detected at the time after immunisation when this histological feature was infrequent (Fig. 8). At later periods, the mononuclear cell infiltration sometimes invaded the submucosa. Granuloma formation was observed in the lamina propria (Figure 9).

The histological analysis of organs other than those belonging to the gut show no pathological alterations. The same was true for the control guinea pigs, either non-immunised or injected with FCA alone, including the intestine (Fig. 10).

In control animals, only a very mild degree of vascular congestion could be detected at the alginate-MA contact areas.

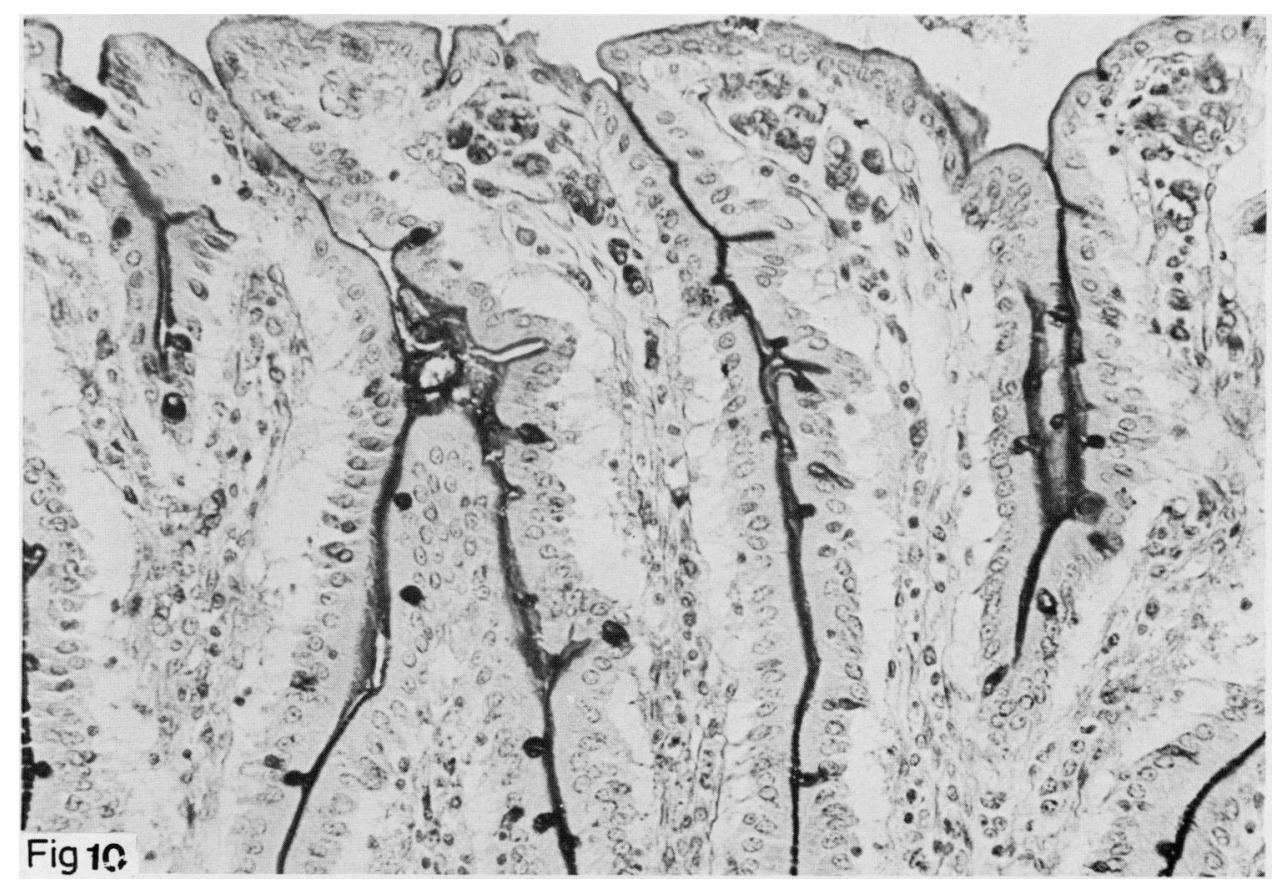

Fig 10 Guinea pigs immunised with 2 doses of FCA alone and killed at day 120. Ileum, near the ileocolic junction. Normal histologic structures. PAS-H. 


\section{Discussion}

The alloimmunisation of outbred guinea pigs with an enteric mucosal protein elicited a complex syndrome in a high percentage of animals. Their immunopathology was compatible with that of an experimental autoimmune disease.

Ulcerohaemorrhagic lesions were the most important alterations in the animals sacrificed shortly after the beginning of immunisation but were present also at the most advanced periods.

Sixty or more days after the beginning of immunisation and after receiving two or more doses of immunogen, cellular proliferation and infiltration with mononuclear cells disrupted the cytoarchitecture of small intestine, caecum and colon.

It is worthwhile to point out that even at the earliest period of the histopathological observations - that is, 30 days after a single dose of immunogen, almost all the animals developing lesions showed similar degrees of intensity as illustrated in Figure 2. These observations indicate that the initial lesions appear at periods shorter than 30 days. Current work in our laboratory is trying to find the precise moment of appearance of the lesions as well as their histopathological features.

More than a single dose of immunogen appeared to be necessary in order to obtain detectable levels of precipitant antibodies in sera. Although the technique utilised here was not quantitative, it was observed that the number of animals revealing precipitant antibodies in their sera peaked at 120 days after the beginning of the immunisation and diminished thereafter.

Both 'in vivo' and 'in vitro' cell mediated immune responses specific to the immunogen were observed even 30 days after a single dose of mucosal antigen. At that time, between 80 and $87 \%$ of the experimental animals gave positive responses.

The guinea pigs receiving multiple doses of the immunogen gave positive immune responses only in half of the cases studied, but this percentage applied to all periods, including 225 days after the beginning of immunisation.

Similar combination of humoral and cell mediated immune responses, together with histopathological alterations in target organs has been described in other experimental autoimmune diseases. ${ }^{8}$ In some of these, humoral immune responses or cell-mediate immune events appear to play a more prominent part in the process."

Immunisation with an intestinal glycoprotein in rats $^{4}$ and with heterologous colonic extracts in guinea pigs ${ }^{11}$ provoked immunological and histopathological alterations close to those presented here. A distinctive feature of our results, however, is the wide distribution of lesions along the intestinal tube and the characteristic dynamics of appearance of lesions: acute sloughing of the intestinal mucosa followed at later stages by mononuclear cell infiltration, fibrosis and granuloma formation. This sequence of histopathological events is characteristic of ulcerative colitis and Crohn's disease. ${ }^{11} 12$

Many of the models of non-specific bowel disease are concerned with the appearance of ulcerative lesions in colon or rectum. This is the main feature of lesions obtained by carragenin ingestion in guinea pigs $^{13}$ and rabbits. ${ }^{14}$

Dilute acetic acid applied over the colonic serosa or per rectum in rats ${ }^{15}$ or intraluminally at the caeco-colonic junction in rabbits ${ }^{16}$ provokes a diffuse colitis. Here, the ulceration and some degree of non-specific cellular infiltration are the main features.

In search of a less acute and more chronic type of colitis possessing some of the immunological elements present in inflammatory bowel diseases, Mee et al $^{17}$ combined the immunisation of rabbits with the enterobacterial antigen of Kunin, with the injection of soluble immunocomplexes and a mild irritation of colon with diluted formalin. Still, in this interesting model, the lesions were limited to the colon.

The importance of cell mediated events in some models of inflammatory bowel disease has been stressed by dinitrochlorobenzene sensitisation experiments. ${ }^{18-20}$ Our results obtained in alloimmunised guinea pigs challenged by the intraluminal colonic route, are compatible with an 'in vivo' delayed hypersensitivity reaction of the descending colonic mucosa. A distinctive feature of our observations, however, is that the reaction is accompanied by lesions located in anatomical segments far away from the original contact area with MAalginate.

The possibility is raised that in these experimental groups, a more intense immune response reaches segments not usually targeted, but nevertheless bearer of the putative autoantigen.

Further studies could confirm the usefulness of alloimmunisation with the mucosal antigen immunogen in the guinea pig, as a model for the study of inflammatory bowel disease.

Supported by a grant from the Canadian Foundation for Ileitis \& Colitis (CFCI). The authors acknowledge the skilful technical assistance of Denis Maisonneuve and Robert Dumont and the secretarial help of Ginette Paré. Thanks are due to $\mathrm{A}$ Tirado, DDS who introduced us to the use of alginate and to $\operatorname{Dr} \mathrm{R}$ A Côté for his help and criticism during the writing of the manuscript. 


\section{References}

1 Perlman P, Lagercrantz R, Hammarström S. Lower gastrointestinal system: ulcerative colitis and Crohn's disease (regional enterocolitis). In: Miescher P, MüllerEberhard HJ, eds. Textbook of immunopathology. New York: Grune \& Stratton, 1976; 2: 755-74.

2 Kirsner JB, Shorter RG. Recent developments in nonspecific inflammatory bowel disease. $N$ Engl J Med 1982; 306: 837-48.

3 Rabin RS. Duodenum, Ileum-, and colon-specific antigens. Int Arch Allergy Appl Immunol 1976; 50: 133-41.

4 Roche JK, Cook SL, Day ED. Goblet cell glycoprotein: an organ-specific antigen for gut. Isolation, tissue localization and immune response. Immunology 1981; 44: 799-810.

5 Forstner J, Taichman N, Kalnins V, Forstner G. Intestinal goblet cell mucus: isolation and identification by immunofluorescence of a goblet cell glycoprotein. $J$ Cell Sci 1973; 12: 585-6()2.

6 Lowry OH, Rosebrough WJ, Farr AL, Randall RJ. Protein measurement with the folin phenol reagent. $J$ Biol Chem 1951; 193: 265-75.

7 Munoz J. Double diffusion in plates. In: Williams CA, Chase MW eds. Methods in immunology and immunochemistry. New York: Academic Press, 1978; III: 146-60.

8 Nemirovsky MS. Partial inhibition of cell mediated immunity (CMI) by Niridazole: effect upon development of autoimmune aspermatogenic orchitis (AIAO) in guinea pigs. Am J Reproduc Immunol 1982; 2: 79-86.

9 Weigle WO. Cellular events in experimental autoimmune thyroiditis, allergic encephalomyclitis and toler- ance to self. In: Talal N. ed. Autoimmunity. Genetic, immunologic, virologic and clinical aspects. New York: Academic Press, 1977: 141-70.

10 Rabin BS, Rogers SJ. Transfer of colon inflammatory disease from immune to normal guinea pigs by lymphocytes. Int Arch Allergy Appl Immunol 1980; 63: 201-4.

11 Morson BC. Pathology of ulcerative colitis. In: Kirsner JB, Shorter RG, eds. Inflammatory bowel disease. Philadelphia: Lea \& Febiger, 1980: 281-95.

12 Withehead R. Pathology of Crohn's Disease. In: Kirsner JB, Shorter RG, eds. Inflammatory bowel disease. Philadelphia: Lea \& Febiger, 1980: 296-307.

13 Watt J, Marcus R. Carrageenin-induced ulceration of the large intestine in the guinea pig. Gut 1971; 12: 164-71.

14 Watt J, Marcus R. Hyperplastic mucosal changes in the rabbit colon produced by degraded carrageenin. Gastroenterology 1970; 59: 760-8.

15 McPherson BR, Pfeiffer CJ. Experimental production of diffuse colitis in rats. Digestion 1978; 17: 135-50.

16 Sharon P. Stenson WF. Metabolism of arachidonic acid in acetic acid colitis in rats. Gastroenterology 1985; 88: 55-63.

17 Mee AS, McLaughlin J, Hodgson HJF, Jewell. DP. Chronic immune colitis in rabbits. Gut 1979; 20: 1-5.

18 Askenase PW, Boone WT, Binder HJ. Colonic basophil hypersensitivity. J Immunol 1978; 120: 198-201.

19 Rabin BS, Rogers SJ. A cell-mediated immune model of inflammatory bowel disease in the rabbit. Gastroenterology 1978; 75: 29-33.

20 Glick ME, Falchuk ZM. Dinitrochlorobenzeneinduced colitis in the guinea pig: studies of colonic lamina propria lymphocytes. Gut 1981; 22: 120-5. 